\title{
Route of Epoetin Administration Influences Hemoglobin Variability in Hemodialysis Patients
}

\author{
Tejas Patel $^{b} \quad$ Angie Hirter $^{a} \quad$ James Kaufman $^{c}$ Sai Ram Keithi-Reddy \\ Domenic Reda ${ }^{a}$ Ajay Singh ${ }^{b}$ \\ ${ }^{a}$ Cooperative Studies Program Coordinating Center, Hines VA Hospital, Hines, Ill., benal Division, Brigham and \\ Women's Hospital, Harvard Medical School, and ' Renal Section, VA Boston Healthcare System, Boston, Mass., USA
}

\section{Key Words}

Hemoglobin variability · Anemia · Subcutaneous epoetin •

Bundling of dialysis service

\begin{abstract}
Background: Compared to the intravenous route, subcutaneous administration of epoetin requires lower dose and will be an attractive option for cost containment when bundling for dialysis is implemented. Hemoglobin variability defined as fluctuation of hemoglobin over time has not been well studied with respect to the route of administration. Methods: 157 prevalent-hemodialysis subjects were analyzed from an open-label, randomized study that compared the intravenous to the subcutaneous route of epoetin with identical weight-based dosing algorithm. Hemoglobin variability was defined as the number of weeks hemoglobin is outside the target range of $10-11 \mathrm{~g} / \mathrm{dl}$. Sensitivity analysis was performed. Results: 78 subjects in the intravenous and 79 in the subcutaneous group entered the 24-week dose maintenance phase. Baseline covariates were similar in both groups except for the dose of epoetin (lower in subcutaneous) and dialysis vintage (longer in intravenous). Patients on subcutaneous epoetin were outside the target range more weeks $(p=0.04)$ and had higher standard deviation of hemoglobin $(p=0.01)$ compared to the intravenous group. Conclusions:
\end{abstract}

\section{KARGER}

Fax +41613061234 E-Mail karger@karger.ch www.karger.com
(C) 2008 S. Karger AG, Basel

0250-8095/09/0296-0532\$26.00/0

Accessible online at:

www.karger.com/ajn
The subcutaneous route of epoetin was associated with modestly higher hemoglobin variability, probably reflecting greater sensitivity of the subcutaneous route and/or identical epoetin-dosing algorithm employed in both the arms. This study could serve as an important guide when bundling for dialysis services is implemented as switching from intravenous to subcutaneous administration is likely to occur.

Copyright $\odot 2008$ S. Karger AG, Basel

\section{Introduction}

Anemic hemodialysis (HD) patients are treated with recombinant erythropoietin and published guidelines have recommended specific treatment hemoglobin ( $\mathrm{Hgb})$ targets [1]. Hgb cycling or variability, which represents a fluctuation of $\mathrm{Hgb}$ concentration over time, makes maintaining narrow $\mathrm{Hgb}$ targets challenging [2]. Hgb variability in HD patients has been reported to be associated with adverse clinical outcomes $[3,4]$. Hgb variability may be exacerbated by iron deficiency, inflammation, infection, hospitalization and changes in fluid status [5].

Study Analysis Performed: Hines VA Hospital, Hines, III., USA.
Ajay K. Singh, MB, FRCP

Renal Division, Brigham and Women's Hospital

MRB-4, 75 Francis Street, Boston, MA 02115 (USA)

Tel. +1 617732 5951, Fax +1 6177326392

E-Mail asingh@partners.org 
Compared to intravenous (i.v.) administration of epoetin, the subcutaneous (s.c.) route results in lower bioavailability but likely greater efficiency due to sustained blood epoetin levels [6]. Subcutaneous epoetin requires approximately $30 \%$ lower epoetin dose, which translates into reduced cost of treatment [7]. The most recent KDOQI guidelines favor the i.v. route of administration in HD patients due to convenience [1]. In July 2008, the United States Congress passed H.R. 6331 that outlines the bundling of dialysis services including dialysis-related drugs to be implemented by January 1, 2011 [8]. In light of these changes, dialysis providers are likely to pursue cost-containment strategies, including moderating the dose of epoetin by adopting the s.c. route of administration. Due to sustained blood epoetin levels, the s.c. route may also have the benefit of reducing $\mathrm{Hgb}$ variability; however, there is paucity of data on Hgb variability with respect to the route of administration.

We evaluated the effect of the route of administration on $\mathrm{Hgb}$ variability by performing a post hoc analysis of data from a Veterans Affairs randomized trial comparing i.v. and s.c. routes of epoetin administration over a $24-$ week period in HD subjects treated with epoetin [7]. We utilized different definitions of Hgb variability that have previously been reported $[9,10]$.

\section{Methods}

\section{Patient Population}

The design of the randomized trial has previously been described in detail [8]. In brief, this was a randomized, open-label trial performed at $24 \mathrm{HD}$ units at Veterans Affairs medical centers in the United States from July 1994 to December 1996. A total of 208 subjects on HD for at least 6 months and on epoetin for at least 3 months before entry were enrolled. All subjects were required to have $\mathrm{Hgb}$ of $10-11 \mathrm{~g} / \mathrm{dl}$ while receiving epoetin s.c. or i.v. thrice weekly during the week prior to randomization. All subjects had serum ferritin $\geq 100 \mathrm{ng} / \mathrm{ml}$ and a transferrin saturation $\geq 20 \%$. The institutional review board of each participating institution approved the study. The present study was analyzed by A.H. and D.R., who had full access to the database.

\section{Epoetin Dosing Algorithm}

At the time of the study design, the FDA recommended a target $\mathrm{Hgb}$ of $10-11 \mathrm{~g} / \mathrm{dl}$ and hence the target range was employed in the study. The subjects were randomly assigned to receive epoetin (Epogen ${ }^{\circledR}$, Amgen, Thousand Oaks, Calif., USA) 3 times weekly either s.c. or i.v. In order to determine the lowest epoetin dose necessary to achieve and maintain the target Hgb, after randomization all subjects had their epoetin doses reduced by $50 \%$, but by no more than $60 \mathrm{U} / \mathrm{kg} /$ week, every 6 weeks until the Hgb was $<10 \mathrm{~g} / \mathrm{dl}$ for 2 consecutive weeks. Subsequently, the dose was increased by $30 \mathrm{U} / \mathrm{kg} /$ week every 4 weeks until the $\mathrm{Hgb}$ was at least
$10 \mathrm{~g} / \mathrm{dl}$ for 2 consecutive weeks. The subjects then entered the 24week maintenance phase in which the dose of epoetin was adjusted according to a specific algorithm to maintain the Hgb in the range of $10-11 \mathrm{~g} / \mathrm{dl}$.

(1) If the $\mathrm{Hgb}$ was $<10 \mathrm{~g} / \mathrm{dl}$ for 2 consecutive weeks and had not increased by $\leq 1 \mathrm{~g} / \mathrm{dl}$ in the prior 4 weeks, the dose of epoetin was increased by $10 \mathrm{U} / \mathrm{kg} / \mathrm{dose}$. If the $\mathrm{Hgb}$ was $<10 \mathrm{~g} / \mathrm{dl}$ and had increased by $>1 \mathrm{~g} / \mathrm{dl}$ in the past 4 weeks no dose change was made.

(2) If the $\mathrm{Hgb}$ was $10-11 \mathrm{~g} / \mathrm{dl}$, no change in dose was made.

(3) If the Hgb increased to $>11 \mathrm{~g} / \mathrm{dl}$ for 2 consecutive weeks, the dose was decreased by $10 \mathrm{U} / \mathrm{kg} / \mathrm{dose}$.

Epoetin doses could not be changed more frequently than every 4 weeks. Hgb was measured weekly before the mid-week HD treatment. Epoetin $(10,000 \mathrm{U} / \mathrm{ml})$ was administered on a weightadjusted basis at the end of $\mathrm{HD}$; all doses were rounded to the nearest $100 \mathrm{U}$. All subjects received oral iron supplements (polysaccharide-iron complex, Niferex-150, Schwarz Pharma, Milwaukee, Wisc., USA).

\section{Definitions of $\mathrm{Hgb}$ Variability}

Primary Outcome Measures. (1) Number of Hgb measurements out of the target range, i.e., $<10$ or $>11 \mathrm{~g} / \mathrm{dl}$ during all visits of the dose maintenance phase. (2) Standard deviation (SD) of all $\mathrm{Hgb}$ measurements during all visits of the dose maintenance phase. These definitions were used as primary outcome measures because we felt they had more relevance to clinical practice.

Secondary Outcome Measures. (1) Hgb rapid velocity, defined as the number of times change in Hgb value was greater than 1.0 g/dl within a 4-week period. (2) Hgb excursions, defined as the number of times change in $\mathrm{Hgb}>1.5 \mathrm{~g} / \mathrm{dl}$ within a 4-week period. (3) Positive Hgb overshoot, defined as the number of times the increase in $\mathrm{Hgb}>3.0 \mathrm{~g} / \mathrm{dl}$ within a 4 -week period. (4) Negative $\mathrm{Hgb}$ overshoot, defined as the number of times the decrease in $\mathrm{Hgb}$ was $>3.0 \mathrm{~g} / \mathrm{dl}$ within a 4 -week period.

Statistical Analysis

Continuous outcome measures were analyzed using multiple regression analysis, which compared the two treatment groups adjusting for weight at baseline, since the treatment groups differed. Categorical outcome measures were analyzed similarly using logistic regression analysis. All statistical tests were two-sided and were considered statistically significant if $\mathrm{p} \leq 0.05$. SAS 9.1 (SAS Inc., Cary, N.C., USA) software was employed.

\section{Results}

Of the total of $208 \mathrm{HD}$ subjects enrolled in the study, 157 subjects entered the maintenance phase of treatment. Clinical and demographic characteristics are provided in table 1. Both the i.v. and s.c. arms were similar with respect to key demographic variables. The total epoetin dose in the s.c. epoetin group was significantly lower than in the i.v. epoetin group $(\mathrm{p}<0.001)$. Subjects in the i.v. epoetin group had a longer dialysis vintage compared to s.c. subjects $(4.41 \pm 4.95$ years in i.v. versus $3.05 \pm 2.70$ years in s.c., $\mathrm{p}=0.04)$. 
Table 1. Clinical and demographic characteristics of subjects who entered the maintenance phase

\begin{tabular}{lccc}
\hline & Intravenous $(\mathrm{n}=78)$ & Subcutaneous $(\mathrm{n}=79)$ & $\mathrm{p}$ \\
\hline Age, years & $60.82 \pm 11.93$ & $59.04 \pm 12.77$ & 0.37 \\
Duration of dialysis, years & $4.41 \pm 4.95$ & $3.05 \pm 2.70$ & 0.04 \\
Duration of epoetin therapy, years & $2.23 \pm 1.55$ & $1.92 \pm 1.52$ & 0.21 \\
Average weight, kg & $73.87 \pm 15.59$ & $78.25 \pm 14.76$ & 0.07 \\
Male gender, $\mathrm{n}$ & $77(98.72 \%)$ & $78(98.73 \%)$ & 1.00 \\
Race Caucasian, $\mathrm{n}$ & $18(23.08 \%)$ & $22(27.85 \%)$ & 0.49 \\
Average dose of epoetin therapy, units/kg/session & $49.99 \pm 25.76$ & $36 \pm 19.62$ & $<0.001$ \\
Hgb, g/dl & $10.38 \pm 0.32$ & $10.37 \pm 0.35$ & 0.58 \\
Serum ferritin, ng/ml & $315.56 \pm 223.68$ & $293.39 \pm 179.71$ & 0.50 \\
Serum transferrin saturation, \% & $27.56 \pm 12.90$ & $26.90 \pm 12.16$ & 0.75 \\
Urea reduction ratio, \% & $67.42 \pm 7.13$ & $66.19 \pm 6.82$ & 0.28 \\
\hline
\end{tabular}

Mean \pm SD unless otherwise indicated. To convert to SI units, multiply serum ferritin by $2.247 \mathrm{pmol} / \mathrm{l}$.

\section{Hgb Variability by Route of Administration}

$\mathrm{Hgb}$ variability was assessed by route of epoetin administration. Table 2 depicts the categorical outcome analysis and table 3 shows the continuous outcome analysis of the Hgb variability during the maintenance phase by route of administration. The definitions of Hgb variability have been used previously [9]. In the analysis based on categorical outcome variables, there were no statistically significant differences by route of administration in the number of subjects experiencing Hgb rapid velocity $(\geq 1 \mathrm{~g} / \mathrm{dl}$ over 4 weeks, $\mathrm{p}=0.40), \mathrm{Hgb}$ excursions $(\geq 1.5$ $\mathrm{g} / \mathrm{dl}$ over 4 weeks, $\mathrm{p}=0.38$ ), change in $\mathrm{Hgb}$ by $\geq 2 \mathrm{~g} / \mathrm{dl}$ in 4 weeks ( $\mathrm{p}=0.52)$, positive Hgb overshoot $(\geq 3 \mathrm{~g} / \mathrm{dl}$ in 4 weeks, $\mathrm{p}=0.20$ ) or negative Hgb overshoot $(\geq 3 \mathrm{~g} / \mathrm{dl}$ in 4 weeks, $\mathrm{p}=0.14)$. When continuous outcome measures were used, the number of weeks Hgb values were out of the target range of $10-11 \mathrm{~g} / \mathrm{dl}$ was modestly but significantly higher in the group receiving s.c. administration of epoetin $(13.92 \pm 4.71$ versus $12.45 \pm 4.99, \mathrm{p}=0.04)$, as was the mean $( \pm S D)$ of the patient weekly $\mathrm{Hgb}$ value $(0.84$ \pm 0.35 versus $0.74 \pm 0.27 \mathrm{~g} / \mathrm{dl}, \mathrm{p}=0.01$ ). There were no statistically significant differences when comparing $\mathrm{Hgb}$ variability in the s.c. and i.v. groups with respect to the number of $\mathrm{Hgb}$ rapid velocity events (4.03 versus 3.44, $\mathrm{p}=$ 0.08 ), number of $\mathrm{Hgb}$ excursions (1.49 versus $1.27, \mathrm{p}=$ 0.22 ), number of times $\mathrm{Hgb}$ change of $\geq 2 \mathrm{~g} / \mathrm{dl}$ occurred in a 4 -week period ( 0.71 versus $0.63, \mathrm{p}=0.42)$, number of positive $\mathrm{Hgb}$ overshoots $(0.05$ versus $0.01, \mathrm{p}=0.17)$ and number of negative $\mathrm{Hgb}$ overshoots ( 0.08 versus $0.04, \mathrm{p}=$ 0.18). In summary, both of the continuous measures of variability reached statistical significance, while the categorical measures had a modest trend for higher Hgb variability for the s.c. arm of epoetin administration.
Table 2. Hgb variability by route of administration - categorical outcome analysis

\begin{tabular}{lcll}
\hline & $\begin{array}{l}\text { Intra- } \\
\text { venous } \\
(\mathrm{n}=78)\end{array}$ & $\begin{array}{l}\text { Sub- } \\
\text { cutaneous } \\
(\mathrm{n}=79)\end{array}$ & $\mathrm{p}$ \\
\hline Hgb rapid velocity events $(\geq 1)$ & $69(88.46)$ & $72(91.14)$ & 0.40 \\
Hgb excursions $(\geq 1)$ & $40(51.28)$ & $44(55.70)$ & 0.38 \\
Hgb changed 2 g in 4 weeks $(\geq 1)$ & $25(32.05)$ & $27(34.18)$ & 0.52 \\
Hgb overshoot $(\geq 1)$ & $1(1.28)$ & $4(5.06)$ & 0.20 \\
Hgb undershoot $(\geq 1)$ & $3(3.85)$ & $6(7.59)$ & 0.14 \\
\hline
\end{tabular}

Data are the number and percentage (in parentheses) of patients having the outcome event at least once during the study period.

There was no difference in the mean total amount of i.v. iron used $(880 \pm 756$ versus $981 \pm 610 \mathrm{mg}$ per patient, i.v. versus s.c., $\mathrm{p}=0.36$ ) or mean number of hospitalizations $(0.65 \pm 1.14$ versus $0.75 \pm 1.23$, i.v. versus s.c., $\mathrm{p}=$ 0.62 ) by route of administration during the maintenance phase.

\section{Hgb Variability in the Cohort as a Whole}

The magnitude of $\mathrm{Hgb}$ variability using different definitions during the 24 -week maintenance phase combining the two treatment groups is shown in table 4 . The mean $( \pm S D)$ number of weeks the Hgb concentration was $<10$ or $>11 \mathrm{~g} / \mathrm{dl}$ was $13.19 \pm 4.89$ over 24 potential $\mathrm{Hgb}$ measurement periods or $55 \%$ of the time. The mean SD was $0.79 \mathrm{~g} / \mathrm{dl}$. The median number of $\mathrm{Hgb}$ excursions per subject over the 24-week period was 1.0 
Table 3. Hgb variability by route of administration - continuous outcome analysis (mean $\pm \mathrm{SD}$ )

\begin{tabular}{lrrr}
\hline & \multicolumn{1}{l}{$\begin{array}{l}\text { Intravenous } \\
(\mathrm{n}=78)\end{array}$} & $\begin{array}{l}\text { Subcutaneous } \\
(\mathrm{n}=79)\end{array}$ & $\mathrm{p}$ \\
\hline Hgb SD & $0.74 \pm 0.27$ & $0.84 \pm 0.35$ & 0.01 \\
Number of weeks Hgb $>11 \mathrm{~g} / \mathrm{dl}$ or $<10 \mathrm{~g} / \mathrm{dl}$ & $12.45 \pm 4.99$ & $13.92 \pm 4.71$ & 0.04 \\
Number of Hgb rapid velocity events & $3.44 \pm 2.69$ & $4.03 \pm 2.84$ & 0.08 \\
Number of Hgb excursions & $1.27 \pm 1.70$ & $1.49 \pm 1.85$ & 0.22 \\
Number of times Hgb changed $2 \mathrm{~g} / 4$ weeks & $0.63 \pm 1.17$ & $0.71 \pm 1.22$ & 0.42 \\
Number of Hgb overshoots & $0.01 \pm 0.11$ & $0.05 \pm 0.22$ & 0.17 \\
Number of Hgb undershoots & $0.04 \pm 0.19$ & $0.08 \pm 0.27$ & 0.18 \\
\hline
\end{tabular}

Table 4. Hgb variability in all subjects entering maintenance phase (combined s.c. and i.v. routes)

\begin{tabular}{lllllll}
\hline Variable & $\begin{array}{l}\text { Number of } \\
\text { SD of all Hgb }\end{array}$ & $\begin{array}{l}\text { Number of weeks } \\
\text { Hgb }<10 \text { or } \\
>11 \mathrm{~g} / \mathrm{dl}\end{array}$ & $\begin{array}{l}\text { Number of } \\
\text { Hgb rapid } \\
\text { velocity events }\end{array}$ & $\begin{array}{l}\text { Number of } \\
\text { Hgb } \\
\text { excursions }\end{array}$ & $\begin{array}{l}\text { Number of } \\
\text { positive } \\
\text { Hgb overshoots }\end{array}$ & $\begin{array}{l}\text { Number of } \\
\text { negative } \\
\text { Hgbershoots }\end{array}$ \\
\hline Mean & 0.79 & 13.19 & 3.73 & 1.38 & 0.03 & 0.06 \\
Median & 0.74 & 14 & 3 & 1 & 0 & 0 \\
SD & 0.32 & 4.89 & 2.78 & 1.77 & 0.18 & 0.23 \\
5th percentile & 0.37 & 5 & 0 & 0 & 0 & 0 \\
25th percentile & 0.56 & 9 & 2 & 0 & 0 & 0 \\
75th percentile & 0.96 & 17 & 5 & 2 & 0 & 0 \\
95th percentile & 1.42 & 21 & 9 & 5 & 0 & 1 \\
\hline
\end{tabular}

with no measurable positive and negative Hgb overshoots. The median number of $\mathrm{Hgb}$ rapid velocity events was 3.0.

\section{Discussion}

The main findings of our study were that over a 24week maintenance period Hgb variability was slightly higher in the s.c. route compared to the i.v. route of epoetin administration. These marginal differences achieved statistical significance in the two continuous measures but in none of the categorical measures. This is due to the increased statistical power inherent in continuous outcome measures; however, the clinical significance of these differences may be small. Overall, the study population had their weekly $\mathrm{Hgb}$ outside the target range of $10-11 \mathrm{~g} / \mathrm{dl}$ approximately $55 \%$ of the time over the $24-$ week dose maintenance period.

The effect of the route of administration on Hgb variability has not been well studied. A small study almost a decade ago evaluated hematocrit stability by route of administration in dialysis patients [11]. Forty-one patients were switched from the i.v. to the s.c. route of epoetin administration and followed for 24 weeks. Compared to 4 weeks of i.v. treatment, the authors found that the s.c. route for the period of weeks 21-24 (4-week period) had lower hematocrit stability (defined as pooled SD of hematocrit, SD of 1.37 in i.v. versus 2.02 in s.c., $\mathrm{p}<0.001$ ). The study had small sample size, employed arbitrary period of evaluation and lacked sensitivity analysis. The study also did not report the iron status and other comorbid conditions. Most importantly, the study did not give information on epoetin dosing algorithm. In contrast, our study had strict enrollment criteria, documentation of iron status and evaluated $\mathrm{Hgb}$ variability for the entire study period. We performed sensitivity analysis to confirm our findings. The epoetin dosing protocol was clearly stated and was identical in both the arms. Thus, the magnitude of SD for Hgb in our study was modest ( 0.79 in the cohort as a whole, 0.74 in i.v. and 0.82 in s.c. group) and lower than previously reported. We postulate that strict adherence to our conservative epoetin dosing algorithm with changes in epoetin doses of about $800 \mathrm{U} /$ dose accounted for the smaller magnitude of the SD for Hgb, compared to that reported in other studies. The number of epoetin dose adjustments in our study was not different between the arms $(\mathrm{p}=0.23)$. 
Hence, it is reasonable to conclude that the number of dose adjustments did not play a role in Hgb variability in our study.

The small but significant difference in Hgb variability between i.v. and s.c. routes of administration may have several mechanistic explanations. Although the s.c. route of epoetin administration results in sustained erythropoietin levels in the blood, there is a wide range $(18-80 \%)$ of bioavailability - largely because of differences in absorption from the s.c. tissue [12]. Another possible explanation for the slightly higher Hgb variability observed with the s.c. route in our study is the specific epoetin-dosing algorithm we employed. The doses were adjusted by an absolute amount rather than as a percentage of the previously prescribed dose with identical algorithms used in both arms. Because epoetin by the s.c. route has a longer half-life, the change in Hgb may be greater for a given dose change compared to the i.v. route. Hence, it is plausible that the s.c. route algorithm may require smaller incremental dose changes compared to the i.v. route.

$\mathrm{Hgb}$ variability has been reported to be associated with adverse outcomes. Ebben et al. [13] observed Hgb variability to be associated with higher hospitalization and a higher number of comorbid conditions in a 6month period. Yang et al. [3] reported that Hgb variability (defined by residual SD of $\mathrm{Hgb}$ ) had a 33\% increase in risk of death for each $1 \mathrm{~g} / \mathrm{dl} \mathrm{Hgb}$ increase in residual SD. A more recent study by the same group employed marginal structural modeling to adjust for time-dependent confounding. The authors found a hazard ratio of 1.93 for each gram per deciliter increase in $\mathrm{Hgb}$ variability [4].

Maintaining the Hgb level within a prespecified target range is challenging. In HD patients, a large study found only $10.3 \%$ of subjects remained in a stable $\mathrm{Hgb}$ range and $6.5 \%$ in the target range of $11-12.5 \mathrm{~g} / \mathrm{dl}$ over a 6-month period [13]. In a single-center retrospective study of $208 \mathrm{HD}$ patients receiving i.v. epoetin evaluated over a 1-year duration, $90 \%$ of patients demonstrated $\mathrm{Hgb}$ variability (defined as $\mathrm{Hgb}$ change $>1.5 \mathrm{~g} / \mathrm{dl}$ over $>8$ weeks). There were $3.1 \mathrm{Hgb}$ excursions per subject (defined as half of one Hgb cycle) over the study period [9]. In our study $\mathrm{Hgb}$ variability was observed less frequently (Hgb was outside the target range in $55 \%$ of subjects over a 6-month period and the mean number of Hgb excursions was 1.38). Several factors may account for our reduced $\mathrm{Hgb}$ variability including participation in a randomized trial requiring adherence to a specified dosing algorithm, limiting the magnitude and frequency of epoetin dose changes, lower Hgb targets and ensuring the adequacy of iron stores.

Since the original study reported significant hypothetical cost savings with s.c. epoetin compared to i.v., the present study did not explore economic analysis. Switching from i.v. to s.c. may result in substantial cost savings. Hynes et al. [14] estimated that a 32\% reduction in epoetin dose with s.c. administration would allow Medicare cost savings of USD 2,987-4,095 per patient (the calculation assumed a Medicare-allowed rate of USD 10/1,000 units). In another analysis, the average cost savings per year of drug alone was approximately $30 \%$, or USD 1,761 per patient year (1,998 dollars) [7]. A separate analysis showed a saving of USD 47-142 million annually if 25$75 \%$ of patients on $\mathrm{HD}$ were switched from i.v. to s.c. and a $50 \%$ dose reduction in all such patients would save an estimated USD 295 million annually [15].

The study was not designed to address clinical significance of $\mathrm{Hgb}$ variability. However, epidemiologic studies suggest that $\mathrm{Hgb}$ variability may be associated with adverse clinical outcomes. The present study evaluated only epoetin- $\alpha$ preparation and hence the findings cannot be extrapolated to the longer acting erythropoiesis-stimulating agents. Finally, we did not report patient satisfaction as this was already reported in the original publication - although most patients preferred the i.v. route of administration, patient discomfort was comparable between the s.c. and the i.v. route of administration.

The strengths of the study included the use of identical $\mathrm{Hgb}$ targets and epoetin-dosing algorithms in both arms in prevalent HD patients. Furthermore, because of the randomized design both groups were balanced with respect to demographic and clinical parameters. Subjects were required to have ferritin $>100 \mathrm{ng} / \mathrm{ml}$, thus minimizing iron deficiency, one of the primary variables that may affect $\mathrm{Hgb}$ variability, further allowing us to evaluate the influence of the route of administration on Hgb variability. Our study was a post hoc analysis of a randomized trial; we controlled for various factors, including treatment algorithm, thus providing better assessment between the two routes of administrations. Since the study had relatively modest sample size, we performed sensitivity analyses using different definitions of $\mathrm{Hgb}$ variability and the trend was similar.

In conclusion, our study demonstrates that $\mathrm{Hgb}$ variability was slightly higher in the s.c. route of epoetin administration. While Hgb variability in the entire group was common it was less so than in previous reports. These findings will serve as an important guide when bundling 
of ESRD services occurs. If a dialysis unit decides to switch patients from i.v. to s.c. administration, we suggest that there should be careful consideration of dosing algorithms and potentially smaller dose changes with s.c. administration in order to minimize $\mathrm{Hgb}$ variability.

\section{Acknowledgments}

Dr. Patel was supported by T32-DK007527-23. The analysis for the present study was supported in part by the Cooperative Studies Program of the Department of Veterans Affairs Office of Research and Development.

\section{References}

1 KDOQI Clinical Practice Guideline and Clinical Practice Recommendations for Anemia in Chronic Kidney Disease: 2007 update of hemoglobin target. Am J Kidney Dis 2007;50:471-530.

-2 Gilbertson DT, Ebben JP, Foley RN, Weinhandl ED, Bradbury BD, Collins AJ: Hemoglobin level variability: associations with mortality. Clin J Am Soc Nephrol 2008;3: 133-138.

3 Yang W, Israni RK, Brunelli SM, Joffe MM, Fishbane S, Feldman HI: Hemoglobin variability and mortality in ESRD. J Am Soc Nephrol 2007;18:3164-3170.

-4 Brunelli SM, Joffe MM, Israni RK, Yang W, Fishbane S, Berns JS, Feldman HI: Historyadjusted marginal structural analysis of the association between hemoglobin variability and mortality among chronic hemodialysis patients. Clin J Am Soc Nephrol 2008;3:777782 .

5 Fishbane S, Berns JS: Evidence and implications of haemoglobin cycling in anaemia management. Nephrol Dial Transplant 2007; 22:2129-2132.
Besarab A: Optimizing epoetin therapy in end-stage renal disease: the case for subcutaneous administration. Am J Kidney Dis 1993;22:13-22.

-7 Kaufman JS, Reda DJ, Fye CL, Goldfarb DS, Henderson WG, Kleinman JG, Vaamonde CA: Subcutaneous compared with intravenous epoetin in patients receiving hemodialysis. Department of Veterans Affairs Cooperative Study Group on Erythropoietin in Hemodialysis Patients. N Engl J Med 1998; 339:578-583.

$8 \mathrm{Http}: / /$ thomas.Loc.Gov/cgi-bin/query/ f?C110: 8:./temp/ c110acfglu:E1131 (accessed August 27, 2008).

-9 Fishbane S, Berns JS: Hemoglobin cycling in hemodialysis patients treated with recombinant human erythropoietin. Kidney Int 2005;68:1337-1343.

10 Lacson E Jr, Ofsthun N, Lazarus JM: Effect of variability in anemia management on hemoglobin outcomes in ESRD. Am J Kidney Dis 2003;41:111-124. $\checkmark 11$ Goodkin DA, Gimenez LF, Graber SE, Van Stone JC, Egrie JC, Okamoto DM: Hematocrit stability following intravenous versus subcutaneous administration of epoetin alfa to dialysis patients: a post hoc analysis. Clin Nephrol 1999;51:367-372.

12 Salmonson T, Danielson BG, Wikstrom B: The pharmacokinetics of recombinant human erythropoietin after intravenous and subcutaneous administration to healthy subjects. Br J Clin Pharmacol 1990;29:709713.

13 Ebben JP, Gilbertson DT, Foley RN, Collins AJ: Hemoglobin level variability: associations with comorbidity, intercurrent events, and hospitalizations. Clin J Am Soc Nephrol 2006;1:1205-1210

14 Hynes DM, Stroupe KT, Greer JW, Reda DJ, Frankenfield DL, Kaufman JS, Henderson WG, Owen WF, Rocco MV, Wish JB, Kang J, Feussner JR: Potential cost savings of erythropoietin administration in end-stage renal disease. Am J Med 2002;112:169-175.

15 Knauss MD, Walton T, Macon EJ: Switching from i.v. to s.c. epoetin in hemodialysis patients. Am J Health Syst Pharm 2002;59: 1783-1784. 